\title{
ORIGINAL ARTICLE GENDER AND REGIONAL DISPARITIES IN EMERGENCY ARRHYTHMIA PROCEDURES DURING COVID-19 LOCKDOWN
}

\author{
Pir Sheeraz Ali ${ }^{1}$, Sarah Mansoor $^{2}$, Azam Shafquat ${ }^{1}$ \\ ${ }^{1}$ National Institute of Cardiovascular Diseases, Karachi, Pakistan, ${ }^{2}$ Aga Khan University Hospital, Karachi, Pakistan
}

Objectives: Worldwide reduction in emergency procedures has been observed during the current COVID-19 pandemic. The effects of the pandemic and its associated lockdown on arrhythmia related emergency procedures is not known. This study was done to see the effects of the COVID-19 pandemic lockdown on provision of emergency arrhythmia procedures and to identify vulnerable patient groups that may be disproportionately affected during lockdown. Methodology: Data for patients requiring emergency intracardiac devices including temporary and permanent pacemakers was collected from three public sector hospitals of Sindh, Pakistan, for the COVID-19 lockdown period of March to May 2020. This was compared to the data for the same period for 2019.

Results: Patients presenting during lockdown decreased by $32.8 \%$ (from 250 to 168) compared to the same period without lockdown. The decline was across all emergency procedures considered. There was a more than fivefold reduction in the number of patients in patients from outside the metropolitan area of the hospital (64.3\%) compared to those residing within the city $(12.5 \%)(\mathrm{p}=0.001)$. There was a trend showing women to be more effected, with the percentage decline in women being statistically significant in the rural setting $(-93.8 \%$ vs. $-52.9 \%$, $\mathrm{p}=0.043)$. All age groups were equally affected $(\mathrm{p}=0.152)$.

Conclusion: A marked reduction in the number of patients who presented for emergency intra cardiac devices and TPM procedures was seen during COVID-19 lockdown. The patients who presented from outside the city of the hospital and women in rural setting were significantly more effected.

Keywords: COVID-19, Temporary Pacemakers (TPM), Permanent Pacemakers (PPM), Women health, CIED (Cardiovascular Implantable Electronic Device), Heart Block

Citation: Ali PS, Mansoor S, Shafquat A. Gender and Regional Disparities in Emergency Arrhythmia Procedures During COVID-19 Lockdown. Pak Heart J. 2021;54(04):344-347. DOI: https://doi.org/10.47144/phj.v54i4.2181

\section{INTRODUCTION}

Temporary (TPM) and permanent pacemakers (PPM) and implantable cardioverter-defibrillators (ICDs) are potentially life-saving procedures for arrhythmia patients presenting in the emergency department. A $25-40 \%$ decrease of emergency presentation of ST elevation myocardial infarction has been seen all over the world since the start of the COVID-19 pandemic. ${ }^{1-}$ ${ }^{4}$ Similarly multiple reports have shown a decrease in hospital admissions for emergency surgeries like appendectomies, cholecystectomies, bowel resections, amputations $^{5}$ in addition to acute coronary syndrome ${ }^{6}$ and stroke. ${ }^{7}$

Electrophysiology (EP) labs in several cities affected by the pandemic showed that only a minimum number of elective EP procedures were performed. ${ }^{8}$ There is no data on patients with cardiac rhythm problems requiring emergency procedures.

A lockdown with stay at home instructions similar to many regions in the world was issued in Sindh province, Pakistan from $23^{\text {rd }}$ March 2020 which ended on $10^{\text {th }}$ May 2020. All businesses and public transport including intra- and inter- city bus and train services were restricted. However all emergency departments in hospitals continued to function. This study was done to see the effects of the COVID pandemic lockdown on emergency arrhythmia procedures and to identify vulnerable patient groups that may be disproportionately affected by lockdown measures.

\section{METHODOLOGY}

A retrospective study was conducted using admissions and billing data at a public sector Hospitals. Hospital and its satellites constitute a group of 10 hospitals performing procedures in the province of Sindh (population 48 million as per census of 2018 conducted by the Population Welfare Department). Device implantations are carried out at Karachi and Sukkur (urban) and Tando Mohammad Khan (TMK) (rural) hospitals.

Patients admitted through the emergency room who required temporary or permanent pacemakers or ICDs between March 23rd 2020 and May 10th 2020 (Lockdown group) and the same time period in 2019 (No Lockdown group) were included. Baseline demographics and procedure details were collected. 
Elective admissions and patients presenting from outpatients department, and those below 18 years of age were excluded.

The primary outcome was change in number of patients presenting through emergency department for electrophysiology procedures (TPM, PPM and ICD implants) in the lockdown period as compared to those presenting during the same time duration in 2019. Quantitative variables like age were calculated as mean and standard deviation. Qualitative variables like procedure performed and gender were calculated as frequency and percentage. Tests were conducted to see relationship between demographic variables and change in number of patients seeking emergency care.

The research reported in this article adhered to Declaration of Helsinki guidelines, and the study was approved by the institutional review board. Need for informed consent was waived by the board due to the retrospective nature of the study. The data was deidentified for to protect confidentiality.

Collected data were analyzed using IBM SPSS version 21.0. The two timeframes, i.e. during and before COVID-19 lockdown were compared for the number of procedures, type of procedures, geographic distribution, and demographic distribution by conducting independent sample t-test or Chi-square test. Percentage decline in the number of procedures were compared for various baseline characteristics by conducting Chi-square test. Statistical significance criteria was kept as $\mathrm{p} \leq 0.05$ for all comparisons.

\section{RESULTS}

A total of 418 patients (519 procedures) were included in the study with an average age of $63 \pm 12$ years. $43.8 \%$ of these were women. The average age and sex distribution in both groups was similar (Table 1). During the lock down period there was a $32 \%$ decrease in number of patients (250 to 168 ) requiring emergency temporary and permanent cardiovascular implantable electronic device (CIED) procedures compared to the same time period in 2019 (Table 1).

The total number of procedures decreased from 322 to $197(-38.8 \%)$ (Table 1). The decline in emergency presentation of patients was seen across all procedures and numbers were similarly decreased for cardiac resynchronization therapy (CRT), ICDs permanent and temporary pacemakers (see Figure 1).

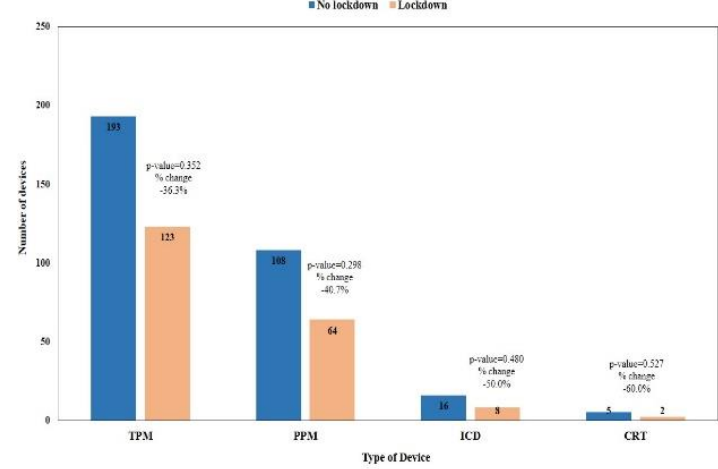

Figure 1: Effect of COVID lockdown on number of procedures by device type

$C R T=$ Cardiac Resynchronization Therapy Device, $I C D=$ Implantablel Cardioverter-Defibrillator, $\quad P P M=$ Permanent Pacemaker, TPM = Temporary Pacemaker

Decline in number of patients was seen across all demographic groups but some groups were more significantly affected. Overall decrease was similar between sexes and across different age groups (See Table 1). However the decline in patients was more than fivefold for those residing outside the city limits of the hospital $(-64 \%)$ compared to those residing within it $(12.5 \%$; $\mathrm{p}=0.001)$.

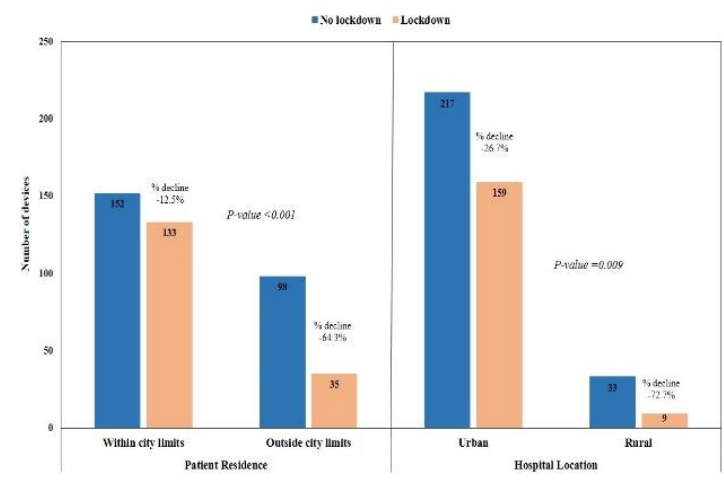

Figure 2. Comparison of percentage decrease in patients by patient residence and hospital location

Similarly the decline was more in the rural setting where the number of patients decreased by 72 percent compared to an urban setting with the number decreasing by 26 percent $(\mathrm{p}=0.009)$ (Figure 2). Though there was a trend for the decline to be more in women than men at all hospitals but this was more pronounced in the rural setting with the number of women declining by $93.8 \%$ vs. $52.9 \%$ for men ( $\mathrm{p}=$ 0.043) (Figure3). 
Table 1: Demographic distribution and type devices implanted stratified by COVID-19 lockdown status

\begin{tabular}{|c|c|c|c|c|c|}
\hline \multirow{2}{*}{$\begin{array}{l}\text { Charact } \\
\text { eristics }\end{array}$} & \multirow{2}{*}{ Total } & \multicolumn{2}{|c|}{ Lockdown status } & \multirow{2}{*}{$\Delta$} & \multirow{2}{*}{$\begin{array}{c}\text { p- } \\
\text { value }\end{array}$} \\
\hline & & No & Yes & & \\
\hline Total & 418 & 250 & 168 & -82 & - \\
\hline \multicolumn{6}{|l|}{ Gender } \\
\hline Female & $\begin{array}{c}43.8 \% \\
(183)\end{array}$ & $\begin{array}{c}44.8 \% \\
(112)\end{array}$ & $\begin{array}{c}42.3 \% \\
(71)\end{array}$ & $\begin{array}{c}-36.6 \% \\
(-41)\end{array}$ & \multirow{2}{*}{0.608} \\
\hline Male & $\begin{array}{c}56.2 \% \\
(235)\end{array}$ & $\begin{array}{c}55.2 \% \\
(138)\end{array}$ & $\begin{array}{c}57.7 \% \\
(97)\end{array}$ & $\begin{array}{c}-29.7 \% \\
(-41)\end{array}$ & \\
\hline $\begin{array}{l}\text { Age } \\
\text { (years) }\end{array}$ & $\begin{array}{c}63.38 \pm \\
12.39\end{array}$ & $\begin{array}{c}62.53 \pm \\
12.43\end{array}$ & $\begin{array}{c}64.64 \pm \\
12.27\end{array}$ & - & 0.088 \\
\hline $\begin{array}{l}23 \text { to } 55 \\
\text { years }\end{array}$ & $\begin{array}{c}25.4 \% \\
(106)\end{array}$ & $\begin{array}{l}28 \% \\
(70)\end{array}$ & $\begin{array}{c}21.4 \% \\
(36)\end{array}$ & $\begin{array}{c}-48.6 \% \\
(-34)\end{array}$ & \multirow{4}{*}{0.240} \\
\hline $\begin{array}{l}56 \text { to } 64 \\
\text { years }\end{array}$ & $\begin{array}{c}23.9 \% \\
(100)\end{array}$ & $\begin{array}{l}22 \% \\
(55)\end{array}$ & $\begin{array}{c}26.8 \% \\
(45)\end{array}$ & $\begin{array}{c}-18.2 \% \\
(-10)\end{array}$ & \\
\hline $\begin{array}{l}65 \text { to } 70 \\
\text { years }\end{array}$ & $\begin{array}{c}25.8 \% \\
(108)\end{array}$ & $\begin{array}{c}27.2 \% \\
(68)\end{array}$ & $\begin{array}{c}23.8 \% \\
(40)\end{array}$ & $\begin{array}{c}-41.2 \% \\
(-28)\end{array}$ & \\
\hline $\begin{array}{l}71 \text { to } 98 \\
\text { years }\end{array}$ & $\begin{array}{c}24.9 \% \\
(104)\end{array}$ & $\begin{array}{c}22.8 \% \\
(57)\end{array}$ & $\begin{array}{l}28 \% \\
(47)\end{array}$ & $\begin{array}{c}-17.5 \% \\
(-10)\end{array}$ & \\
\hline \multicolumn{6}{|c|}{ Type of device } \\
\hline TPM & $\begin{array}{c}75.6 \% \\
(316)\end{array}$ & $\begin{array}{c}77.2 \% \\
(193)\end{array}$ & $\begin{array}{c}73.2 \% \\
(123)\end{array}$ & $\begin{array}{c}-36.3 \% \\
(-70)\end{array}$ & 0.352 \\
\hline PPM & $\begin{array}{c}41.1 \% \\
(172)\end{array}$ & $\begin{array}{c}43.2 \% \\
(108)\end{array}$ & $\begin{array}{c}38.1 \% \\
(64)\end{array}$ & $\begin{array}{c}-40.7 \% \\
(-44)\end{array}$ & 0.298 \\
\hline ICD & $\begin{array}{l}5.7 \% \\
(24)\end{array}$ & $\begin{array}{c}6.4 \% \\
(16)\end{array}$ & $\begin{array}{c}4.8 \% \\
(8)\end{array}$ & $\begin{array}{c}-50 \% \\
(-8)\end{array}$ & 0.480 \\
\hline CRT & $\begin{array}{c}1.7 \% \\
(7)\end{array}$ & $2 \%(5)$ & $\begin{array}{c}1.2 \% \\
(2)\end{array}$ & $\begin{array}{c}-60 \% \\
(-3)\end{array}$ & 0.527 \\
\hline \multicolumn{6}{|c|}{ Patient Residence within Hospital City/Town } \\
\hline $\begin{array}{l}\text { Within } \\
\text { city }\end{array}$ & $\begin{array}{c}68.2 \% \\
(285)\end{array}$ & $\begin{array}{c}60.8 \% \\
(152)\end{array}$ & $\begin{array}{c}79.2 \% \\
(133)\end{array}$ & $\begin{array}{c}-12.5 \% \\
(-19)\end{array}$ & \multirow{2}{*}{$\begin{array}{c}<0.00 \\
1\end{array}$} \\
\hline $\begin{array}{l}\text { Out of } \\
\text { city }\end{array}$ & $\begin{array}{c}31.8 \% \\
(133)\end{array}$ & $\begin{array}{c}39.2 \% \\
(98)\end{array}$ & $\begin{array}{c}20.8 \% \\
(35)\end{array}$ & $\begin{array}{c}-64.3 \% \\
(-63)\end{array}$ & \\
\hline \multicolumn{6}{|l|}{ Location } \\
\hline Urban & $\begin{array}{l}90 \% \\
(376)\end{array}$ & $\begin{array}{c}86.8 \% \\
(217)\end{array}$ & $\begin{array}{c}94.6 \% \\
(159)\end{array}$ & $\begin{array}{c}-26.7 \% \\
(-58)\end{array}$ & \multirow{2}{*}{0.009} \\
\hline Rural & $\begin{array}{l}10 \% \\
(42)\end{array}$ & $\begin{array}{c}13.2 \% \\
(33)\end{array}$ & $\begin{array}{c}5.4 \% \\
(9)\end{array}$ & $\begin{array}{c}-72.7 \% \\
(-24)\end{array}$ & \\
\hline
\end{tabular}

$C R T=$ Cardiac Resynchronization Therapy Device, $I C D=$ Implantablel Cardioverter-Defibrillator, $P$ PM=Permanent Pacemaker, TPM = Temporary Pacemaker

$\Delta=$ decreased during lockdown

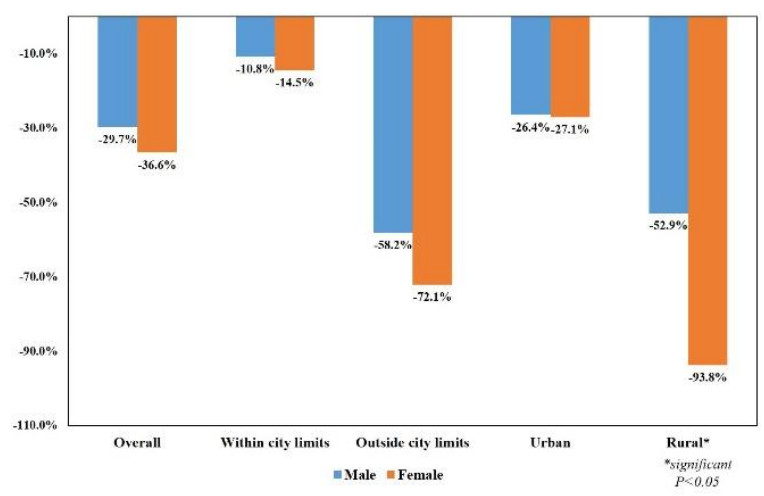

Figure 3. Percentage decrease in number of cases by sex, based on patient residence (within or outside city limits of the hospital) and hospital location (urban or rural) in number of cases $(*=p$ value $\leq \mathbf{0 . 0 5}$ )

\section{DISCUSSION}

Our hospital with its network of 10 hospitals is the principal provider of emergency cardiac services in the province of Sindh. This study was done to see the effects of the COVID-19 pandemic and lockdown on utilization of emergency arrhythmia procedures and to identify vulnerable patient groups that may be disproportionately affected by lockdown measures.

Despite a higher reported prevalence of cardiovascular diseases among those with COVID-19 we describe a significant decline in number of patients with cardiac arrhythmias requiring emergency procedures. These findings are consistent with the decline seen in patients with ACS and other emergency conditions reported all over the world. ${ }^{1,6,7}$

There may be several causes for a decrease in the numbers. Strict stay at home orders imposed by the authorities restricted patients from leaving their homes to receive health care. Patients may have preferred to stay home and consult doctors via telemedicine clinics as its role had been advocated by both the government and international societies. ${ }^{9} 10$ Even though a recent study has shown that risk of acquiring the infection is minimal during emergency arrhythmia procedures, ${ }^{11}$ patients fear of nosocomial acquisition of infection may have acted as a deterrent as well. Another potential deterrent for patients and their relatives could be the fear of acquiring the coronavirus infection at the hospital. ${ }^{12}$

The major group that has been affected in our study is those that reside geographically further away from the hospital. Those patients whose residence was not within the city or town limits of the hospital were less likely to seek care, with only a third of the number presenting during the lockdown period. This was statistically significant when compared to patients who resided within the city as $88 \%$ of these patients showed up at the hospital. There may be multiple causes for this difference between the two populations. Non- availability of intercity transport and fear of going to an unfamiliar region in times of social stress, along with closure of hotels for accompanying family members may have dissuaded patients from seeking care. Many patients stay with family members working in the city but with all businesses being closed and workers going to their home towns these informal arrangements were also in jeopardy. Loss of income due to the pandemic with reduced finances available to fund longer travel may also have been a factor in limiting such patients. 
Although the proportional decrease between men and women was statistically similar, the decline trend was more in women. This disproportionate decrease in women was most pronounced and significant in those seeking care in the rural setting where the number of women decreased by $93 \%$ compared to men who decreased by $52 \%$. One reason for this may be difficulty of bringing additional people to the hospital (women culturally require a female chaperone in addition to a male accompanying them).

A common theme across the groups with a disproportionately higher decline in patients (living outside the city limits of the hospital, rural setting and women) is that they are generally considered to be socially weaker and likely to be more disadvantaged. The poverty rate in rural Pakistan is twice as much as in urban areas and female literacy rate is half of urban centres. $^{13}$ Patients who belong to disadvantaged groups are the ones who most suffer in times of social stress and the findings of this study correlate with this

This study is an important addition to the growing literature on healthcare access and provision during COVID-19. It highlights the change in health seeking behavior and its disproportionate effects on members of society who already have poor access to healthcare like women and patients residing in rural areas. Based on our study, increased awareness needs to be created amongst general public to ensure that the patients requiring care are brought to the hospital. Government measures enforcing lockdown need to ensure that vulnerable sections of the society are not disproportionately affected by blanket restrictions.

\section{CONCLUSION}

A significant decline in the number of emergency TPM and CIED procedures has been seen during COVID-19 pandemic. Patients residing outside city limits of the hospital, and women seeking emergency care in a rural setting are disproportionately affected. Patient awareness of symptoms and lockdown measures that ensure provision of facilities to the vulnerable portion of society need to be encouraged. Further studied are needed to determine the exact causes of this decline.

\section{AUTHORS' CONTRIBUTION:}

PSA and AS contributed to the concept and design of study, PSA and AS contributed to the collection, analysis and interpretation of data, PSA, SM, and AS contributed to the drafting of the manuscript, and JAS, TS, and ASA critically analyzed for content. All authors have read and approved the manuscript.

Conflict of interest: Authors declared no conflict of interest.

Acknowledgment: The authors wish to acknowledge the support of the staff members of the Clinical Research Department of the National Institute of Cardiovascular Diseases (NICVD) Karachi, Pakistan.

\section{REFERENCES}

1. Garcia S, Albaghdadi MS, Meraj PM, Schmidt C, Garberich R, Jaffer FA, et al. Reduction in ST-segment elevation cardiac catheterization laboratory activations in the United States during COVID-19 pandemic. J Am Coll Cardiol. 2020;75(22):2871-2.

2. Rodríguez-Leor O, Cid-Álvarez B, Ojeda S, Martín-Moreiras J, Rumoroso JR, López-Palop R, et al. Impacto de la pandemia de COVID-19 sobre la actividad asistencial en cardiología intervencionista en España. REC Interv Cardiol. 2020;2:82-9.

3. Tam CC, Cheung KS, Lam S, Wong A, Yung A, Sze M, et al. Impact of coronavirus disease 2019 (COVID-19) outbreak on STsegment-elevation myocardial infarction care in Hong Kong, China. Circ Cardiovasc Qual Outcomes. 2020;13(4):e006631.

4. Roffi M, Guagliumi G, Ibanez B. The Obstacle Course of Reperfusion for ST-Segment-Elevation Myocardial Infarction in the COVID-19 Pandemic. Circulation. 2020;141(24):1951-3.

5. Patriti A, Eugeni E, Guerra F. What happened to surgical emergencies in the era of COVID-19 outbreak? Considerations of surgeons working in an Italian COVID-19 red zone. Updates Surg. 2020;72(2):309-10

6. Metzler B, Siostrzonek P, Binder RK, Bauer A, Reinstadler SJ. Decline of acute coronary syndrome admissions in Austria since the outbreak of COVID-19: the pandemic response causes cardiac collateral damage. Eur Heart J. 2020;41(19):1852-3.

7. Markus HS, Brainin M. COVID-19 and stroke-A global World Stroke Organization perspective. Int J Stroke. 2020;15(4):361-4.

8. Li J, Mazzone P, Leung LW, Lin W, D’Angelo G, Ma J, et al. Electrophysiology in the time of coronavirus: coping with the great wave. Europace. 2020;22(12):1841-7.

9. Lakkireddy DR, Chung MK, Gopinathannair R, Patton KK, Gluckman TJ, Turagam M, et al. Guidance for Cardiac Electrophysiology During the COVID-19 Pandemic from the Heart Rhythm Society COVID-19 Task Force; Electrophysiology Section of the American College of Cardiology; and the Electrocardiography and Arrhythmias Committee of the Council on Clinical Cardiology, American Heart Association. Circulation. 2020;141(21):e823-31.

10. Wosik J, Fudim M, Cameron B, Gellad ZF, Cho A, Phinned D, et al. Telehealth Transformation: COVID-19 and rise of Virtual care. J Am Med Inform Assoc. 2020;27(6):957-62.

11. Workman V, Freeman JV, Obasare ER, Jain S, Ganeshan R, Burr A, et al. Risk of COVID-19 Infection After Cardiac Electrophysiology Procedures. Heart Rhythm O2. 2020;1(4):23942.

12. Seifi A, Stowers JA, Behrouz R. Fewer Hospital Visits for Acute Stroke and Acute Coronary Syndrome During the COVID-19 Pandemic: A Reality or a Myth?. J Neurol Res. 2020;10(3):53-5.

13. World Bank. When Water Becomes a Hazard: A Diagnostic Report on The State of Water Supply, Sanitation, and Poverty in Pakistan and Its Impact on Child Stunting. World Bank; 2018.

\section{Address for Correspondence:}

Dr. Azam Shafquat, Professor of Electrophysiology at National Institute of Cardiovascular Diseases (NICVD), Rafiqui (H.J.) Shaheed Road, Karachi- 75510, Pakistan.

Email: azamshafquat@gmail.com 